TRABAJO Y TRABAJADORES:

RED LATINOAMERICANA

\title{
A Farda e o Fardo: Memórias sobre o mundo do trabalho na construção da Usina Hidrelétrica Binacional de Itaipu (1975-1991)
}

\author{
EDUARDO GONÇALVES UEDA
}

Universidade Federal de São Paulo, Guarulhos, Brasil

eduardouedda@gmail.com

\section{ENDRICA GERALDO}

Universidade Federal da Integração Latino-Americana, Foz do Iguaçu, Brasil endrica.geraldo@unila.edu.br

Resumo: Este artigo pretende demonstrar a existência de disputas em torno de uma memória sobre o lugar e o papel dos trabalhadores na construção da Usina Hidrelétrica Binacional de Itaipu na fronteira entre o Brasil e o Paraguai nas décadas de 1970 a 1990. A partir da análise de discursos e entrevistas concedidas ao longo da construção da hidrelétrica por autoridades relacionadas à administração da obra e pelos chefes de Estado, além das publicações do informativo de circulação interna produzido pelo consórcio de empreiteiras UNICON, pretendemos evidenciar o esforço por parte da administração da obra e da empresa, assim como de membros do regime, em controlar -no período e atualmente- a narrativa em torno da construção e em definir uma memória dos trabalhadores. Finalmente, discutiremos como a realização de entrevistas com trabalhadores tem revelado outras perspectivas que contribuem para o aprofundamento dos debates e análises sobre os temas relacionados ao mundo do trabalho.

Palabras-chave: memória, trabalhadores, Itaipu Binacional, ditadura civil-militar

Recebido: 31 de março de 2020. Aprovado: 9 de junho de 2020. 


\section{Introdução}

O presente artigo trata de um processo de disputa pelas memórias em torno da construção da Usina Hidrelétrica Binacional de Itaipu no Rio Paraná, realizada na divisa entre a cidade brasileira de Foz do Iguaçu e o distrito de Hernandarias, localizado nas proximidades da então Puerto Presidente Stroessner, atual Ciudad del Este, Paraguai. A região é também conhecida como Tríplice Fronteira, pois o encontro entre os rios Paraná e Iguaçu marcam a divisa entre a cidade argentina de Puerto Iguazú (localizada na província de Misiones, na região nordeste do país), Foz do Iguaçu (cidade situada no extremo oeste do Estado do Paraná, região sul do Brasil), e Ciudad del Este (no extremo leste do Paraguai e capital do Departamento de Alto Paraná). A construção ocorreu entre 1975 e 1991 e, durante a maior parte desse período, Brasil e Paraguai estavam sob ditaduras militares.

O objetivo é discutir as evidências do processo pelo qual autoridades da ditadura civil-militar brasileira e representantes da administração da obra procuraram formular e controlar, desde o início, a narrativa em torno da construção e até mesmo organizar uma memória sobre o papel dos trabalhadores. Para isso, analisaremos inicialmente como os discursos oficiais, entrevistas e publicações produzidas pelos administradores da obra, incluindo o consórcio brasileiro de construtoras (UNICON), procuraram forjar um conjunto de representações que, posteriormente, iria formar uma memória institucional. Em seguida, discutiremos sobre como novas pesquisas, assim como entrevistas realizadas com antigos trabalhadores, têm contribuído para problematizar elementos importantes dessa memória e da história da construção, colaborando para os debates sobre as transformações nas condições de vida e trabalho de indivíduos e famílias que, no caso específico de Itaipu, contribuíram para a formação da classe trabalhadora iguaçuense nos anos de construção da barragem.

A ditadura do general Alfredo Stroessner no Paraguai, uma das mais longas da América Latina, teve início em 1954 e se estendeu até 1989. O período foi marcado por projetos de desenvolvimento nacional, envolvendo a atração de investimentos estrangeiros em infraestrutura com o objetivo de romper o isolamento nacional e possibilitar a exploração econômica da região leste do país. ${ }^{1}$ Ao longo de seu governo, Stroessner procurou desenvolver uma aproximação com o Brasil por meio de acordos que aumentaram a influência brasileira no Paraguai em contraposição ao papel até então exercido pela

1 John Howard White, "Itaipú: gender, community, and work in the Alto Paraná borderlands, Brazil and Paraguay, 1954-1989” (PhD Diss. University of New Mexico, 2010), 88-89. 
Argentina. A aproximação produziu, entre outros resultados, a construção da Ponte da Amizade ${ }^{2}$ entre a cidade brasileira de Foz do Iguaçu e a atual cidade paraguaia de Ciudad del Este, além da construção da rodovia brasileira (BR277, inaugurada em março de 1969) que possibilitou a interligação entre ou Foz do Iguaçu e ao porto brasileiro de Paranaguá, com saída para o oceano Atlântico, diminuindo a dependência paraguaia com relação aos portos argentinos. Além disso, houve a participação da empreiteira brasileira CBPO (Companhia Brasileira de Projeto e Obras) na construção da Usina Hidrelétrica de Acaray, a primeira do Paraguai, inaugurada em 1968, indicando o aumento da atuação das construtoras brasileiras na região. ${ }^{3}$ Assim, a construção da hidrelétrica de Itaipu iria reunir alguns dos interesses geopolíticos e econômicos do governo do Paraguai, que desejava atrair investimentos, acordos comerciais e a tecnologia brasileira voltada para obras de infraestrutura, enquanto ao Brasil interessava intensificar sua influência na região do Cone Sul, consolidando um papel de potência regional, além de promover internamente o crescimento do setor de energia elétrica (mesmo em regiões distantes dos mercados consumidores), ${ }^{4}$ e proporcionar a expansão da atuação das construtoras brasileiras especialmente na América Latina. ${ }^{5}$

Os estudos sobre a viabilidade do aproveitamento dos recursos hídricos do Rio Paraná para a produção de energia elétrica no território brasileiro iniciaram-se em 1955, com especial interesse pelo trecho dos Saltos das Sete Quedas, zona de litígio entre o Paraguai e o Brasil. Houve projetos de

2 Segundo Silva e Dias Júnior, o Brasil financiou e foi responsável pela construção da Ponte da Amizade, que liga a cidade brasileira de Foz do Iguaçu com a atual cidade paraguaia de Ciudad del Este. A construção foi iniciada em 1956 e uma inauguração simbólica ocorreu em 1961 por Stroessner e o então presidente brasileiro Juscelino Kubitschek (1956-1961). Em março de 1965, Stroessner e o marechal Castelo Branco, primeiro presidente da ditadura brasileira e que governou entre 1964 e 1967, inauguraram oficialmente a obra, com a habilitação para o trânsito de pessoas e de veículos. Paulo Renato da Silva e Waldson de Almeida Dias Júnior, “O ‘progresso’ e a ‘falta’: representações e relações BrasilParaguai no jornal O Globo durante a construção da Ponte da Amizade (19561965)", Revista Territórios \& Fronteiras 12, no 2 (2019): 7-8.

3 White, "Itaipú: gender, community", 90-91.

4. Ivone Teresinha Carletto de Lima, Itaipu: as faces de um mega projeto de desenvolvimento (1930-1984) (Niterói: Editora Germânica, 2004), 96.

5 Campos menciona que mesmo entre os anos de 1969 e 1975, quando ocorreu o auge da demanda interna de obras públicas no Brasil, as empreiteiras brasileiras buscaram oportunidades no exterior, dando início ao processo de transnacionalização do setor, com destaque para sua inserção na América Latina, entre outras regiões. Pedro Henrique Pedreira Campos, "O processo de transnacionalização das empreiteiras brasileiras, 1969-2010: uma abordagem quantitativa", Tensões Mundiais 10, nº 18 e 19 (2014): 114. 
aproveitamento dos Saltos que mantinham a hidrelétrica em território estritamente brasileiro, no entanto o projeto de hidrelétrica que melhor parecia resolver o litígio de fronteiras entre o Brasil e o Paraguai, e que ainda colocava o Paraguai sob a órbita de influência do Brasil era o do empreendimento binacional, que reconhecia os recursos hídricos do Rio Paraná como pertencentes em condomínio aos dois países, posição consolidada na Ata de Iguaçu (1966). ${ }^{6}$

De acordo com o brasileiro Paulo Schilling e o paraguaio Ricardo Canese, a solução binacional, em detrimento da nacional, não foi baseada em questões técnicas, mas sim realizada como manobra geopolítica: "Somente à luz da geopolítica explica-se perfeitamente o que parece ser totalmente absurdo do ponto de vista técnico, econômico, diplomático ou humano". ${ }^{7}$ Era uma estratégia do Estado brasileiro para consolidar sua influência sobre o Paraguai e isolar a Argentina. Em outubro de 1978, o jornal Folha de São Paulo publicou a afirmação do então presidente da República, o general Ernesto Geisel, de que a Itaipu era um “ $[\ldots]$ projeto coerente que combinava com a imagem [que] os últimos governos brasileiros fortes fazem do Brasil - uma Nação forte, e tão poderosa que se vê no centro metropolitano de poder regional". ${ }^{8}$ Assim, o projeto final de Itaipu manifestava a imagem que as autoridades do regime militar brasileiro procuravam projetar: a imagem de um país forte e uma potência regional.

O general Costa Cavalcanti, primeiro diretor-geral da Itaipu (cargo que ocupou entre 1974 e 1985), ${ }^{9}$ em pronunciamento para representantes da Assembleia Legislativa do Paraná no ano de 1979, afirmou que para "romper com os grilhões do subdesenvolvimento" era preciso "lançar mão dos recursos naturais que possuímos, dos avanços tecnológicos conhecidos e da capacidade de nossa gente". ${ }^{10}$ Naquele momento, a obra representava a

6 Documento assinado pelo embaixador do Brasil, Juracy Magalhães, e o Ministro das Relações Exteriores do Paraguai, Doutor Raúl Sapena Pastor, em 1966. Itaipu, Atos Oficiais da Itaipu Binacional (Curitiba, PR: Itaipu Binacional, 2005), 15-17. O documento também é conhecido como Ata das Cataratas.

7 Paulo Schilling e Ricardo Canese, Itaipu: geopolítica e corrup̧̧ão (São Paulo: CEDI, 1991), 23-25, citado em Maria de Fátima Bento Ribeiro, "Itaipu, a dança das águas: histórias e memórias de 1966 a 1984” (Tese de Doutorado, UNICAMP, 2006), 46.

8 Schilling e Canese, Itaipu: geopolítica, 23-25, citado em Ribeiro, "Itaipu, a dança das águas", 46.

9 Lima, Itaipu: as faces, 206.

10 Pronunciamento do Diretor-Geral Brasileiro de Itaipu Gen. Costa Cavalcanti no dia 29/06/1979. Ribeiro, "Itaipu, a dança das águas", 127. De acordo com Ribeiro, o pronunciamento foi dirigido aos representantes da Assembleia Legislativa do Paraná, que estavam em visita à Itaipu para acompanhar o 
eficiência dos governantes em elaborar e executar um projeto gigantesco que estaria destinado a contribuir de forma significativa para o desenvolvimento nacional.

Em razão da grandiosidade do projeto que deu origem à maior usina hidrelétrica do mundo, ${ }^{11}$ consórcios foram formados para executar as obras de construção civil e a montagem eletromecânica. As obras de construção civil da Itaipu ficaram a cargo da União de Construtoras Ltda (UNICON), que reuniu cinco construtoras brasileiras, e o Consórcio de Empresas Construtoras Paraguaias (CONEMPA), com seis empresas. ${ }^{12}$ No presente estudo, nosso foco recai sobre o consórcio brasileiro - integrado pela CBPO (Cia. Brasileira de Pavimentos e Obras); Camargo Corrêa; Cetenco Engenharia Ltda; Andrade Gutierrez; e Mendes Júnior - e o processo de elaboração de uma memória institucional, em grande medida antagônica à experiência dos trabalhadores que migraram para a cidade, e que se consolidou como uma memória dominante. Pelo menos desde a publicação do estudo de Dreifuss evidenciando as relações entre parcelas da sociedade civil com o golpe militar de 1964 no Brasil, pesquisadores têm aprofundado as análises sobre o papel desempenhado pelos empresários, e mais especificamente pelos empreiteiros, durante a Ditadura. O historiador Pedro Campos analisou a natureza dessas relações, destacando diversos casos de apoio explícito aos aparatos de repressão da ditadura por parte de

processo de construção da obra. Maria de Fátima Bento Ribeiro, Memórias do Concreto: vozes na construção de Itaipu (Cascavel: Edunioeste, 2002), 26.

11 Em 2012, a China concluiu a construção da Usina de Três Gargantas, que é maior e supera Itaipu em potência instalada, mas Itaipu atualmente produz mais energia. Itaipu Binacional, “A maior geradora de energia limpa e renovável do planeta”, https://www.itaipu.gov.br/energia/comparacoes (27/03/2020).

12 A CONEMPA foi um consórcio paraguaio especializado na construção civil composto pelas empresas A Barrail Hermanos; Cia. General de Construcciones; ECCA S.A.; Ing. Civil Hermanos Baumam; Ecomipa - Emp. Const. Min. Paraguaya; e Jimenez Gaona \& Lima. Além desses, havia os consórcios responsáveis pela montagem eletromecânica: o brasileiro ITAMON, composto pelas empresas A. Araújo S.A. - Engenharia e Montagem; Empresa Brasileira de Engenharia S.A. - EBE; Montreal Engenharia S.A.; Sade - Sul Americana de Engenharia S.A.; Sertep - Engenharia e Montagem S.A.; Techint - Companhia Técnica Internacional; Tenenge - Técnica Nacional de Engenharia S.A.; e Ultratec Engenharia S.A. e o paraguaio CIEE composto pelas empresas AG Brown Boveri \& Cie; Alstom Atlantique; Bardella S.A. Indústrias Mecânicas; BSI - Indústrias Mecânicas S.A.; Brown Boveri \& Cie. AG; Indústria Elétrica Brown Boveri S.A.; J.M. Voith GmbH; Mecânica Pesada S.A.; Neyrpic; Siemens Aktiengesellschaft; Siemens S.A.; e Voith S.A. Máquinas e Equipamentos. Lima, Itaipu: as faces, 216; e Itaipu Binacional, "Perguntas frequentes", https://www.itaipu.gov.br/sala-de-imprensa/perguntas-frequentes (Acessado em 21/07/2020). 
empreiteiros como Sebastião Camargo, dono da Camargo Corrêa. Por sua vez, os empreiteiros foram amplamente beneficiados pelas políticas implementadas pela ditadura, com a realização de várias obras públicas ao longo do regime. ${ }^{13}$

A gestão do orçamento público também beneficiava esses empresários, como explica Campos, pois o aumento do orçamento relacionado a investimentos nos Ministérios dos Transportes e de Minas e Energia foi proporcional à redução no Ministério da Saúde e no da Educação e Cultura. Além disso, o regime militar também favoreceu o enriquecimento dessa fração de classe "com fartos financiamentos públicos, a partir da captação de crédito internacional - extremamente farto, principalmente no período inicial da ditadura e que levou à elevação drástica do endividamento do Estado brasileiro" ${ }^{14}$

Em contrapartida, Campos argumenta que o golpe de 1964 significou uma derrota para os trabalhadores brasileiros em geral em razão da adoção de medidas de "contenção dos salários, fim da estabilidade nas empresas privadas, instituição de poupanças compulsórias, fim do direito de greve e política de repressão sindical". ${ }^{15}$ Entre os diversos sindicatos que sofreram intervenções na ditadura, com cassações, afastamentos e nomeação de interventores, estavam os da construção civil, e os salários reais no setor tiveram queda em toda a década de 1970. ${ }^{16}$ Além disso, segundo o autor, com a contenção da justiça trabalhista e a reformulação do sistema previdenciário, o índice de acidentes de trabalho cresceu substancialmente, estatística liderada pelo setor da construção. As políticas da ditadura teriam precarizado a fiscalização e contribuído para determinar o uso de recursos públicos para diminuir os índices de acidentes, sem onerar os patrões. Para completar, era comum nas empresas do setor que a culpa pelos acidentes fosse atribuída ao trabalhador. Apesar do contexto repressivo, Campos destaca a ocorrência de diversos conflitos com mobilizações, revoltas, rebeliões e quebra-quebras realizados pelos trabalhadores. A Camargo Corrêa acumulava sublevações e insatisfações e, em 1980, por exemplo, notícias divulgavam a "sublevação na

13 Pedro Henrique Pedreira Campos, Estranhas catedrais: as empreiteiras brasileiras e a ditadura civil-militar, 1964-1988 (Niterói: Eduff, 2014), 107-127. A menção ao trabalho de René A. Dreifuss se refere à obra "1964: a conquista do Estado”, publicada em 1981.

14 Pedro Henrique Pedreira Campos, "Empresariado e ditadura no Brasil: o estado atual da questão e o caso dos empreiteiros de obras públicas”, Transversos:

Revista de História, n. 12, (2018), 353.

15 Campos, Estranhas Catedrais, 355.

16 Ibid., 356. 
segunda maior obra do país, a hidrelétrica de Tucuruí”, que estava a cargo exclusivo desta empreiteira. ${ }^{17}$

Por fim, de acordo com o autor, o Estado também favoreceu os empresários do setor da construção pesada com políticas de repressão e perseguição a organizações e mobilizações de trabalhadores, bem como com o chamado arrocho salarial entre os anos 1964-1974. Essa redução no valor do salário dos trabalhadores significava um substancial aumento nas taxas de lucro de empresas como "Camargo Corrêa, Mendes Júnior, Andrade Gutierrez e Odebrecht [que] mantinham dezenas de milhares de operários em seus canteiros de obras”. ${ }^{18}$ No caso da Itaipu, os interesses dos militares no poder, assim como os da administração da Binacional e os dos empresários da construção civil, articulavam-se na elaboração de uma narrativa homogênea sobre a construção da usina como projeto fundamental para o desenvolvimento nacional.

\section{Construindo os marcos históricos}

É a partir da visão dos dirigentes buscando garantir o cumprimento das etapas do calendário de obras que se estrutura a memória institucional, ainda hoje difundida pela Itaipu. A escolha dos marcos históricos revela o que a administração entendia ser relevante para integrar a história da hidrelétrica. Em 1983, Costa Cavalcanti, então Diretor Geral da Itaipu, em entrevista concedida para Milton Travassos, selecionou os "grandes momentos" da história de Itaipu até a sua inauguração: o desvio do Rio Paraná em 1978; o fechamento das comportas do desvio no mesmo ano; a abertura do vertedouro e o funcionamento da primeira unidade geradora em 1982. ${ }^{19}$

É possível observar como os sucessos de engenharia e de administração são reificados por meio da seleção de datas oficiais e da realização de cerimônias solenes para compor a história da obra. As cerimônias não são realizadas porque essas datas são importantes, mas, pelo contrário, elas se tornam marcos pela realização das cerimônias. De acordo com Pierre Nora, somente dois tipos de acontecimentos constituem um lugar de memória: o “acontecimento fundador” - "os acontecimentos, por vezes ínfimos, apenas notados no momento, mas aos quais, em contraste, o futuro

17 Ibid., 361-367.

18 Campos, "Empresariado e ditadura", 353-354.

19 Milton Travassos, "Entrevista Gen. José Costa Cavalcanti”, Revista Círculo de Engenharia Militar XXXV, no 86 (1983): 17, citado em Ribeiro, "Itaipu, a dança das águas”, 23-24. 
retrospectivamente conferiu a grandiosidade das origens, a solenidade das rupturas inaugurais", e o "acontecimento espetáculo” - "os acontecimentos onde, no limite, nada acontece, mas que são imediatamente carregados de um sentido simbólico e que são eles próprios, no instante de seu desenvolvimento, sua própria comemoração antecipada”. ${ }^{20}$ Nesse sentido, os marcos históricos estabelecidos pela administração de Itaipu incorporam um pouco dos dois tipos de acontecimentos. Tanto o aspecto do espetáculo presente nas cerimônias, quanto pelo prestígio alcançado ao longo do tempo, a equipe administrativa traduziu eventos técnicos em espetáculos, constituindo-os como marcos fundamentais da narrativa histórica de Itaipu, inclusive com o constante destaque para o fato de que se tratava da construção da maior Usina Hidrelétrica do mundo. Essa tradução acompanhou o processo de construção da obra nas cerimônias e nos registros do periódico de circulação interna ao canteiro de obras, o Informativo UNICON, e foi reafirmada ao longo do tempo, como na fala já mencionada do general Costa Cavalcanti.

Em registros como a Ata das Cataratas e o Informativo UNICON, ${ }^{21}$ podemos notar uma preocupação por parte dos administradores da obra articulados com os militares no poder em estabelecer seu domínio sobre as representações em torno de Itaipu. Além disso, entrevistas e discursos oficiais expressam também o processo de construção de uma matriz de interpretação que destaca dois elementos: a harmonia da empreitada binacional e a celebração do cumprimento de etapas como expressão de eficiência do próprio regime militar. Essa associação entre a obra e o regime alcançou importância ainda maior durante o período de contração do setor de construção e contingenciamento de verbas públicas, em oposição ao que ficou conhecido como "milagre econômico" (entre os finais da década de 1960 e início da de 1970 como período de grande crescimento econômico do país). O corte de verbas levou à interrupção de várias obras já nos finais da década de 1970 . Entretanto, aquelas consideradas como as grandes obras da ditadura, como Itaipu, tornaram-se prioridades selecionadas no orçamento mesmo durante o período de estagnação e até de retração no setor, pelo menos até $1988 .^{22}$ Assim, alguns acontecimentos, como os recordes de lançamento de concreto, e datas de conclusão de etapas da construção, como foi o caso do momento de

20 Pierre Nora, "Entre memória e história: a problemática dos lugares", Projeto História 10 (1993): 25-26.

21 O Informativo UNICON foi um periódico bilíngue (espanhol e português), com publicação inicialmente quinzenal, produzido pelo Consórcio UNICON e com circulação interna ao canteiro de obras. O informativo foi publicado entre 1978 e 1988.

22 Campos, Estranhas catedrais, 120-121. 
abertura do canal do desvio, são utilizados como pilares de sustentação dessa interpretação que deu origem à memória institucional difundida ainda hoje pela Binacional.

Seguindo à risca o calendário de obras, os chefes de estado do Brasil e Paraguai, os generais Ernesto Geisel e Alfredo Stroessner, reuniram-se em outubro de 1978 para a suntuosa solenidade de explosão das ensacadeiras, realizando a abertura do canal de desvio do Rio Paraná. Nesta ocasião, Geisel realizou um discurso onde apresentou a eficácia que brasileiros e paraguaios tiveram no cumprimento dos prazos estabelecidos, e elogia uma suposta "equidade que orientou este projeto e sua concretização e, de maneira muito especial, a vontade inquebrantável com que enfrentamos unidos todos os problemas inerentes a uma iniciativa de tal envergadura". ${ }^{23}$ Essa mesma representação harmônica das relações entre brasileiros e paraguaios pode ser encontrada na Ata das Cataratas, que inaugura a narrativa de uma empreitada de "dois povos irmãos". Nesse documento: "Manifestaram-se acordes os dois Chanceleres em reafirmar a tradicional amizade entre os dois Povos irmãos, amizade fundada no respeito mútuo e que constitui a base indestrutível das relações entre os dois países". ${ }^{24}$

Também em 1978 o Informativo UNICON reproduziu uma narrativa semelhante:

[…] estamos plenamente certos de que, absolutamente todos, somos indispensáveis na construção desta Usina, onde homens e máquinas, músculos e argamassa, se fortalecem ao calor de duras jornadas de garra e sacrifício, dando a exata dimensão do temperamento vigoroso de duas nações irmãs, que, no mesmo ideal, uniram seus destinos, para conjugar o verbo do trabalho e o verbo do progresso: Paraguai e Brasil. ${ }^{25}$

No final de 1999, vinte e cinco anos depois do início da construção, a Itaipu continuou a tratar a experiência da construção como uma "epopéia vivida por milhares de brasileiros e paraguaios que, nas décadas de 70 e 80, ergueram a maior hidrelétrica do mundo". ${ }^{26}$ É com esta visão que a Assessoria de

23 Discurso proferido pelo então presidente do Brasil, general Ernesto Geisel, publicado pelo Jornal do Commercio em 21/10/78, citado em Ribeiro, "Itaipu, a dança das águas", 37.

24 Itaipu, Atos oficiais, 15.

25 Informativo UNICON, $\mathrm{n}^{\circ} 1$ (04/02/1978), 2. Acervo do Espaço do Barrageiro, Parque Tecnológico de Itaipu, Foz do Iguaçu- PR, Brasil, doravante AEB-PTI.

26 Nilson Monteiro, Itaipu: a luz (Foz do Iguaçu: Ed. Itaipu Binacional/Assessoria de Comunicação Social, 1999), citado em Odirlei Manarin, Peões da barragem: memórias e relações de trabalho dos operários da construção da hidrelétrica de Itaipu1975-1991 (Marechal Cândido Rondon: UNIOESTE, 2008), 26. 
Comunicação Social da Itaipu Binacional produziu o livro "Itaipu, a luz" do jornalista Nilson Monteiro, apresentando uma síntese da história institucional.

Era importante passar a imagem de que a administração era capaz de gerir com competência o canteiro de obras, e o enorme número de trabalhadores, assegurando a execução das etapas da construção sempre dentro dos prazos estabelecidos. Daí a busca por representar o canteiro de obras como um ambiente harmônico, ordenado e eficiente. Para que o cumprimento do cronograma fosse possível, era preciso que dezenas de milhares de trabalhadores mantivessem as obras em andamento 24 horas por dia. ${ }^{27}$ Era do trabalho dessas pessoas que a barragem ia se erguendo e a narrativa institucional incorporou esses trabalhadores como parte da história, mas sempre integrados aos marcos técnicos. De acordo com Manarin, a história difundida pela administração de Itaipu era:

[...] uma história que apresenta suas fases, os desafios, as dificuldades, as conquistas dos engenheiros, o desempenho da equipe administrativa, os números e a grandiosidade da obra. Porém, os trabalhos elaborados pelos operários denominados 'peões da barragem', quase não se fazem presente, e, quando é citada aparece de forma a engrandecer a beleza da obra, homogeneizando e naturalizando os conflitos e as disputas no canteiro de obras. ${ }^{28}$

Ao incorporar os trabalhadores aos marcos históricos da construção (acordos diplomáticos, datas solenes, recordes de produção, etc.), tanto pela narrativa quanto no registro de imagens presentes no Informativo UNICON, as diversas categorias de trabalhadores são homogeneizadas e suas motivações são tomadas como a mesma que a da administração: a produtividade do canteiro de obras. A produtividade era descrita como resultado da eficiência da gestão dos administradores e da bravura dos trabalhadores, chegando ao heroísmo no caso dos que foram vítimas de acidentes fatais de trabalho.

O periódico produzido pelo consórcio UNICON buscou descrever o canteiro de obras como um espaço sem contradições. Tal procedimento sugere que os trabalhadores cumpriam as metas principalmente pela convicção de que esta obra era importante para o desenvolvimento do país. A narrativa era a da coragem e do esforço de homens dedicados a um bem maior: o progresso da nação. Além disso, esta prática possibilitava ocultar os mecanismos de

27 De acordo com Lima, no período de trabalhos mais intensos a construção chegou a contar com mais de 30 mil trabalhadores. Lima, Itaipu: as faces, 239.

28 Manarin, Peões da barragem, 8. 
controle e coerção utilizados pela empresa para manter a produtividade elevada. $\mathrm{O}$ informativo apresentava imagens como a que segue abaixo:

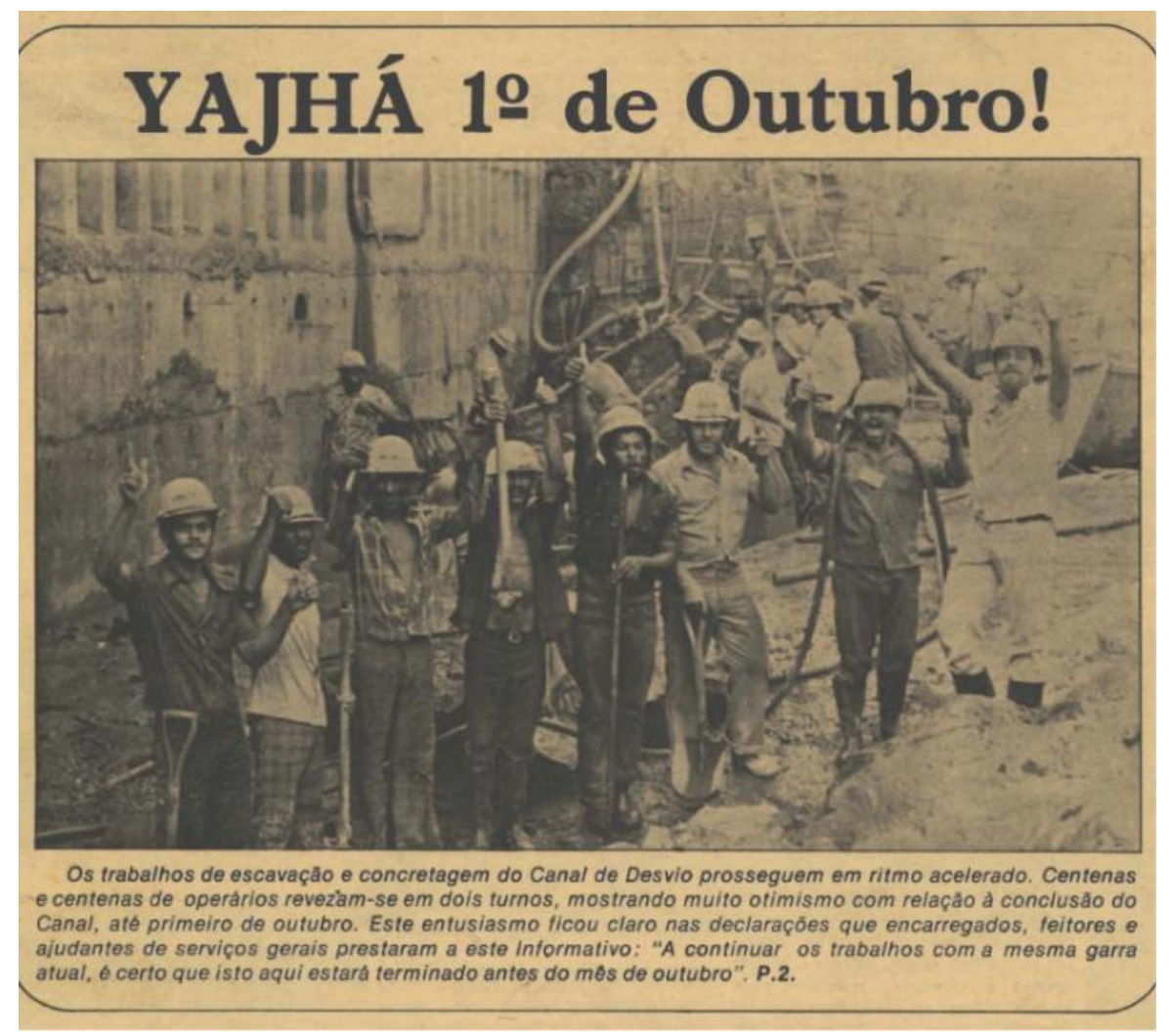

Figura 1: "Yajhá"29

A imagem acompanha a manchete do Informativo UNICON de 4 de fevereiro de 1978, enfatizando gestos de celebração e o suposto entusiasmo e orgulho dos trabalhadores para alcançar a conclusão da etapa de escavações e concretagem do Canal de Desvio do Rio Paraná até outubro do mesmo ano. Vale notar também que, além do fato de que o informativo era produzido em português e espanhol, é possível identificar o uso de termos em guarani, língua muito presente entre os paraguaios, como mais um recurso para demonstrar a integração entre esses trabalhadores e entre as nações. O uso da palavra guarani "Yajhá", traduzida no informativo como "Vamos", sugere a união como caminho para o cumprimento das etapas.

29 "Yajhá", Informativo UNICON, nº 1 (O4/O2/1978), 1. AEB-PTI. 
Por outro lado, o término da etapa do desvio do rio iniciou o "[...] período de rotatividade por causa das demissões". ${ }^{30}$ Para a administração, o término de etapa simbolizava a sua eficiência na condução da obra. Para muitos trabalhadores, significava um grande risco de demissão. Podemos suspeitar, portanto, que os términos de etapa, tão celebrados pela administração, poderia trazer para os trabalhadores o sentimento geral de apreensão e medo das demissões em massa.

Antes mesmo de outubro, já no fim de setembro de 1978, o Canal de Desvio estava pronto. A cerimônia de abertura do Canal de Desvio foi marcada para o dia 20 de outubro. Na edição especial de 18 de outubro do Informativo UNICON, a capa do informativo é o texto "Três Minutos de Silêncio", onde a cerimônia de abertura do canal é evocada e comemorada antecipadamente como um evento transcendental. $\mathrm{O}$ texto narra os três minutos após os presidentes do Brasil e Paraguai, Geisel e Stroessner, apertarem juntos o botão que alertava para a explosão das ensacadeiras. Os três minutos que antecederam a detonação dos explosivos foram retratados no tex to como uma homenagem aos trabalhadores mortos durante a construção:

Faltam três minutos apenas. Enquanto os explosivos não detonam, concentrados em homenagem póstuma, recordemos aqueles que tombaram no cumprimento do dever, envolvidos na sagrada mortalha do suor. Partiram mas, antes, imprimiram suas marcas indeléveis nas faces dos monólitos. As águas têm sensibilidade e hão de beijá-las com todo respeito. ${ }^{31}$

A morte desses indivíduos é retratada como parte de algo que transcende a própria vida dos trabalhadores. Ela é integrada como parte da história da hidrelétrica e como um evento essencial para o desenvolvimento do país, e por isso esses trabalhadores são apresentados como mártires que morreram cumprindo seu dever. Atribui-se aos operários mortos a noção de que estes estavam plenamente convictos de que seu sacrifício não era em vão, de que valia a pena correr os riscos, ou mesmo perder a vida, para que Itaipu cumprisse sua "missão":

Eles não se sacrificaram em vão. Seus familiares entenderão mesmo que doa compreender, nos braços da eternidade, tornaram-se mais lúcidos para dizer de fronte erguida, com maior convicção: meus pais, minha esposa, meus

30 Valdir Sessi, "O Povo do Abismo: Trabalhadores e o aparato repressivo durante a construção da Hidrelétrica de Itaipu (1974-1987)” (Dissertação de mestrado, UNIOESTE, 2015), 178.

31 Informativo UNICON, no 16 (18/10/1978), 1. AEB-PTI. Para muitos trabalhadores, significava um grande risco de demissão. Odirlei Manarin, "Operários de Itaipu. Experiências e lembranças de demissão", História na Fronteira 1, no 2 (2008): 7-26 
filhos, meus amigos, meu povo, Itaipu far-se-á luz para ajudar a dissolver as trevas. $^{32}$

O que a princípio deveria ser uma homenagem aos trabalhadores mortos na obra acaba por relativizar os óbitos diante da importância de Itaipu para o desenvolvimento nacional. Fica evidente que, para o Informativo, as condições emocionais e materiais da família que perdera um ente querido são, de longe, menos importantes do que os resultados da obra de dimensão monumental. A mensagem representa o sentimento das famílias como insignificante diante da imensidão da necessidade da nação por progresso e desenvolvimento. Por fim, para o informativo, os trabalhadores mortos em Itaipu, " $[\ldots]$ tornaram-se bandeiras e heróis de seus filhos aos quais condecoraram para sempre com a medalha do exemplo". ${ }^{33}$ Assim, os trabalhadores são homenageados como heróis patrióticos, mas anônimos, e representados com um papel muito específico, atrelado aos interesses da administração de engrandecer e legitimar o projeto Itaipu.

A ditadura brasileira buscou situar Itaipu como representante do desenvolvimento econômico nacional possível graças ao governo militar. Em se tratando da administração da obra, realizada também por militares, havia a intenção de demarcar a ordem e a eficiência no andamento da construção, assim como a grandeza e o caráter espetacular das obras de engenharia. Desta forma, foram realizadas cerimônias oficiais quando encerrada uma etapa da construção que, tanto pela solenidade do evento quanto pelo olhar retrospectivo da administração sobre esses eventos, criaram marcos históricos associados a uma imagem de eficiência dos militares no exercício do poder. Os trabalhadores também foram incorporados pela narrativa produzida pela instituição, mas de modo secundário e impessoal. Com isso, foi possível ocultar as contradições das relações de trabalho e os diferentes conflitos nas relações hierárquicas e nos contrastes culturais e linguísticos entre brasileiros e paraguaios, bem como entre operários e a equipe administrativa e de segurança, naturalizando o canteiro de obras como um espaço de harmonia, onde todos buscavam cumprir as metas de produtividade.

Ainda nesse sentido, vale destacar que mesmo durante o período democrático houve uma continuidade dessas representações relacionadas aos trabalhadores na história da obra. Em 2010, a Itaipu Binacional desenvolveu um projeto junto com o Parque Tecnológico Itaipu que deu origem ao "Espaço do Barrageiro", com o objetivo de "conceber um espaço para

\footnotetext{
32 Ibid.
}

33 Ibid. 
resgatar, preservar, valorizar e difundir a memória dos barrageiros da Itaipu Binacional", ao "mapear, reunir e guardar o valioso registro histórico de áudio, vídeo e imagem referentes a vida de brasileiros e paraguaios que trabalharam" na construção e integrando esses elementos nas atividades promovidas pelo "Complexo Turístico de Itaipu". ${ }^{34}$ Esta é uma das ações da Binacional para a difusão da sua memória institucional que caracteriza os trabalhadores que ergueram a barragem como "barrageiros", uma categoria de trabalhadores que, supostamente, seriam especializados na construção de barragens. O "Espaço do Barrageiro" está localizado nos antigos alojamentos do canteiro de obras (atualmente os barracões compõem o Parque Tecnológico de Itaipu), inclusive com um quarto caracterizado com os móveis da época, onde ficavam hospedados os trabalhadores solteiros ou desacompanhados de seus familiares.

Dessa forma, o termo "barrageiro" não aparece nessa produção institucional associado apenas ao trabalhador "com experiência em barragens" e normalmente com maior qualificação, mas aos trabalhadores da obra de forma geral. Essa caracterização receberá sua primeira crítica por Odirlei Manarin, que entende que essa categoria não dá conta de explicar a origem dos trabalhadores e nem suas motivações ao chegarem à cidade de Foz do Iguaçu, já que grande parte dos que migraram eram ex-agricultores sem experiência na construção civil..$^{35}$

Em 1982, quando as obras da barragem chegavam ao fim e as comportas do canal do desvio seriam fechadas formando a represa, foi realizada uma cerimônia com os presidentes dos países sócios. Esta data é um marco na história institucional de Itaipu e está inserida na narrativa da eficiência técnica já apresentada. No entanto, esta mesma data ganha outros significados para os agricultores que tiveram suas terras inundadas pelo lago. O evento de represar o Rio Paraná significou para essas famílias a destruição de uma parte de suas tradições e sonhos. As memórias dos agricultores atingidos por Itaipu estão permeadas pelas lutas por indenização justa de suas

34 Os objetivos do projeto estão descritos em: "Museu do barrageiro - Hidrelétrica Itaipu”, Loudness, http://www.loudness.com.br/projetos-especiais/museus-eexposicoes/museu-do-brigadeiro-hidreletrica-itaipu.html (30/03/2020). Ver também: "Espaço do Barrageiro", Parque Tecnológico Itaipu, https://www.pti.org.br/pt-br/espacodobarrageiro (30/03/2020). Apesar do que está descrito nos objetivos, atualmente o Espaço do Barrageiro não consta das atrações oferecidas pelo Centro de Recepção de Visitantes: "Itaipu Binacional - Turismo”, https://www.turismoitaipu.com.br/ (30/03/2020).

35 Manarin, Peões da barragem, 13. 
terras. ${ }^{36}$ Estes são indícios da existência de outros significados atribuídos pela população mais vulnerável de Foz do Iguaçu e pela classe trabalhadora da região a respeito dos processos desencadeados pela construção de Itaipu.

\section{Condição da classe trabalhadora iguaçuense (1970-1990): história e memória}

A construção da barragem de Itaipu atraiu e mobilizou um número gigantesco de trabalhadores. De acordo com os dados do IBGE apresentados por Manarin, na década de 1960 a cidade de Foz do Iguaçu possuía aproximadamente 28 mil habitantes. No início da década de 1970, pouco mais de 33 mil habitantes. A partir de 1975, com o início das obras de Itaipu, a região presenciou um rápido crescimento demográfico e no início da década de 1980 a população de Foz havia saltado para mais de 130 mil habitantes, chegando aos anos 90 com mais de 190 mil. ${ }^{37}$ Notadamente, foi a busca por trabalho diretamente ou indiretamente ligado à obra de Itaipu que em grande medida produziu esse fenômeno.

Indo ao encontro de outros pesquisadores da história da cidade e da construção da hidrelétrica, algumas das entrevistas analisadas no presente artigo, especificamente as com o Sr. David Rezes, o Sr. Marcelo do Iguassu ${ }^{38}$ e o Sr. Adenival Dutra, foram realizadas ao longo da pesquisa desenvolvida entre 2018 e $2019 .{ }^{39}$ No caso das entrevistas com estes trabalhadores, portanto, foi utilizado um roteiro organizado em seis tópicos: 1 . Apresentação; 2. Trajetória familiar na cidade; 3. Trabalho, dando ênfase às condições de trabalho, impressões sobre a rotina, relacionamento com colegas

36 Sobre esta questão, ver: Guiomar Inez Germani, "Memórias da luta dos atingidos por Itaipu", Paraná insurgente: história e lutas sociais - séculos XVIII ao XXI, coord. Joseli M. N. Mendonça e Jhonatan Ueverton Souza (São Leopoldo: Casa Leiria, 2018), 171-187.

37 Manarin, Peões da barragem, 28.

38 Foi utilizado um nome fictício a pedido do entrevistado para garantir seu anonimato.

39 As entrevistas foram realizadas durante pesquisa de Iniciação Científica desenvolvida por Eduardo Gonçalves Ueda sob orientação da Prof. ${ }^{a}$ Dr. ${ }^{a}$ Endrica Geraldo, com bolsa financiada pela UNILA, entre 08/2018 e 07/2019, cujos resultados encontram-se em: Eduardo Gonçalves Ueda, "História e memória dos trabalhadores brasileiros na construção da Usina Hidrelétrica de Itaipu” (Trabalho de Conclusão de Curso, Ciência Política e Sociologia Estado, Sociedade e Política na América Latina, UNILA, 2019). No total foram realizadas 5 entrevistas e 3 são discutidas neste artigo. 
e superiores, dinâmica de contratações e demissões e greves; 4. Identidade; 5. Perspectivas pessoais para o futuro e 6. Agradecimento e encerramento. ${ }^{40}$

A utilização da metodologia da história oral nos permite acessar memórias que não chegam a alcançar a esfera pública, chamadas por Pollak de "memórias subterrâneas" 41 e que por vezes se antagonizam e/ou ressignificam as representações oficiais. Memórias são dotadas de grande importância, seja por se relacionarem com contextos históricos e coletivos, ${ }^{42}$ ou ainda por apresentarem a dimensão subjetiva da perspectiva pessoal de cada entrevistado e pela possibilidade de proporcionarem informação significativa e por vezes a única sobre o passado. ${ }^{43}$

Para atrair a força de trabalho necessária para a cidade, as empreiteiras contaram com sua capilaridade e uso de diversos métodos. Agenciadores contratavam em diversos pontos do país aqueles que tivessem experiência nas funções exigidas para os consórcios. Em geral, procuravam trabalhadores nas construções de barragens que estavam próximas do término. Ao mesmo tempo, anúncios nas rádios e jornais com abrangência nos setores populares informaram sobre as ofertas de emprego. Foi assim, pelo rádio, que o sr. David Rezes (que trabalhou na UNICON e em empresas menores até ser contratado pela Itaipu) tomou conhecimento e interesse pela obra de Itaipu. David se recorda de como ele e seus irmãos vieram para Foz do Iguaçu em 1979 sem nenhum apoio da Itaipu ou empreiteiras: "A gente veio em um paude-arara, veio de baixo de um caminhão com lona, atravessamos... na época funcionava a estrada do colono, cruzando balsa [...] Pagamos um carreto e a gente veio embora" ${ }^{44}$ Além desses mecanismos mais comuns de contratação, os trabalhadores menos experientes estavam sujeitos a serem enganados por agenciadores falsos, chamados de "gatos". De acordo com Cattá, esses "gatos" cobravam um adiantamento dos trabalhadores para

40 A elaboração do roteiro para as entrevistas semi-estruturadas contou ainda com a orientação da Prof ${ }^{a}$. Dr ${ }^{\mathrm{a}}$. Élen Schneider, que também foi coorientadora do trabalho: Ueda, História e memória dos trabalhadores. As entrevistas foram realizadas com gravador de áudio digital e transcritas pelo bolsista seguindo as diretrizes sugeridas em: Verena Alberti, História Oral: a experiência do CPDOC (Rio de Janeiro: Centro de Pesquisa e Documentação de História Contemporânea do Brasil, 1989).

${ }_{41}$ Michael Pollak, "Memória, Esquecimento, Silêncio”, Revista Estudos Históricos 2, no 3 (1989): 4 .

42 Maurice Halbwachs, A Memória Coletiva (São Paulo: Edições Vértice, 1990).

43 Paul Thompson, A Voz do Passado: história oral (Rio de Janeiro: Editora Paz e Terra, 1992), 184.

44 Entrevistado: David Moras Rezes. Entrevistador: Eduardo Gonçalves Ueda, Foz do Iguaçu, 12/04/2019. 
vinculá-los às obras, mas após receber o adiantamento os trabalhadores eram transportados até uma cidade qualquer e eram abandonados. ${ }^{45}$

Para Sessi, “a migração e, posteriormente, as demissões também representavam o aumento do exército de trabalhadores da reserva, estranhos à mobilidade habitual da cidade”. ${ }^{46}$ De outro ângulo: a massiva migração para a cidade teve como efeito o aumento da competitividade no mercado de trabalho, diminuindo os salários, aumentando o custo de vida e, no caso específico de Foz do Iguaçu, desestruturando as antigas relações econômicas da cidade que garantiam a subsistência de setores populares da sociedade, como pequenos agricultores, pescadores e comerciantes de fronteira. ${ }^{47}$

Segundo Aparecida Darc De Souza, a cidade era predominantemente rural até a década de 1970 . E dada à distância da cidade com a capital Curitiba, era comum o comércio de fronteira com Puerto Iguazú, Argentina, como estratégia de sobrevivência adotada pelos moradores:

A população local buscava, na Argentina, produtos industrializados, que não conseguia produzir na cidade nem trazer de Curitiba. A necessidade de abastecimento mobilizava parte considerável da população local, ao ponto de despertar a oferta de serviços de transportes para aqueles que iam para a Argentina. ${ }^{48}$

O relato do senhor Carlos, entrevistado por Souza, explica que a atividade de comércio com Puerto Iguazu encontrava demanda significativa por parte de pequenos comerciantes e dos grandes hotéis. Ele parou com esta atividade por volta da década de 1970, quando o comércio de fronteira passou a ser fiscalizado. A autora entende que essa fiscalização ocorreu por um motivo visível: deveu-se ao contrato realizado entre Brasil e Paraguai para a construção de Itaipu, fato que inviabilizou os planos argentinos de edificar duas usinas hidrelétricas com o Paraguai, acirrando, ainda mais, a postura defensiva que a Argentina assumira em relação ao Brasil, desde a década de 1950.49

45 Luís Eduardo Cattá, "O cotidiano de uma fronteira: A perversidade da modernidade” (Dissertação de mestrado, UFSC, 1994), 64.

46 Sessi, O povo do abismo, 172.

47 Emilio Gonzáles, "Memórias que narram a cidade: Experiências sociais na constituição urbana de Foz do Iguaçu” (Dissertação de mestrado, PUC-SP, 2005).

48 Aparecida Darc de Souza, "Formação econômica e social de Foz do Iguaçu: Um estudo sobre as memórias constitutivas da cidade (1970-2008)" (Tese de Doutorado, USP, 2009), 159.

49 Ibid., 167. 
De acordo com Souza, as ofertas de emprego na cidade antes de Itaipu se conjugavam entre o trabalho assalariado em olarias, madeireiras, serrarias, hotéis e atividade agrícola de subsistência. Este cenário viria a ser drasticamente modificado com o início das obras em 1975. Nos mostra que “[...] para muitos agregados e meeiros que trabalhavam na zona rural, as favelas podem ter sido a única alternativa de moradia, diante da especulação imobiliária que assolava a cidade”. ${ }^{50}$ A senhora Ernestina, entrevistada por Souza, conta: "Era difícil achar casa pra você alugar, e não se achava; tinha que pagar um absurdo, porque Itaipu pagava muito bem, encareceu muito o custo de vida”. ${ }^{51} \mathrm{E}$ o senhor Joaquim afirma: "Naquele tempo, a procura de casa pra você alugá era muito grande, não achava. Pra comprá, nem se fala; era muito grande e caro. Era muito caro um terreno, era muito caro um aluguel de casa... era difícil" [sic]. ${ }^{52}$ Neste ponto se cruzam as trajetórias das pessoas que migraram de muitos lugares do Brasil com aquelas que já viviam em Foz do Iguaçu.

O senhor Marcelo, quando da sua chegada de Goioerê/PR até Foz, viveu um mês na favela Monsenhor Guilherme, próximo à área central da cidade, até construir sua casa no Morumbi, região considerada periférica naquela época. Seu Marcelo, ao relembrar de quando viveu naquele lugar, ressalta a dificuldade encontrada: "Paguei trinta dias de aluguel lá na favela Monsenhor Guilherme. Trinta dias pra mim foi uma eternidade, porque... Deus me perdoe, não querendo desfazer de quem mora em favela, mas é um problema morar em favela”. ${ }^{53}$ Foi o mesmo lugar em que a senhora Margarida viveu por quatro anos, de acordo com Souza, antes das obras de Itaipu, ela vivia com a sua família e dez outras no Rincão São Francisco, onde trabalhavam no cultivo de hortelã e soja. "Eles produziam e pagavam 10\% ao dono da terra. Mas, a partir de 1976, foram expulsos da terra, e, sem alternativas, as famílias se separaram e foram morar nas favelas da cidade”. ${ }^{44}$ A Sra. Margarida também tem más recordações dessa experiência:

$50 \quad$ Ibid., 181.

51 Entrevistado: Carlos. Entrevistadora: Aparecida Darc de Souza, Foz do Iguaçu, 27/03/2007. Souza, Formação econômica e social, 178.

52 Entrevistado: Carlos. Entrevistadora: Aparecida Darc de Souza, Foz do Iguaçu, 27/03/2007. Ibid., 179.

53 O Sr. Marcelo desempenhou diversas funções na UNICON, começando por Ajudante de Serviço até chegar a sub-encarregado. Entrevistado: Marcelo do Iguassu (à pedido do entrevistado, foi mantido o anonimato mediante uso de nome fictício), Entrevistador: Eduardo Gonçalves Ueda, Foz do Iguaçu, 12/04/2019.

54 Entrevistada: Margarida. Entrevistadora: Aparecida Darc de Souza, Foz do Iguaçu, 22/03/2007. Souza, Formação econômica e social, 181. 
Deus o livre! Foi difícil, muito difícil, porque você imagina aquela pessoa que nunca morou na cidade, e ir pra cidade ... que era os ranchinho, não tinha água, que na favela Monsenhor Guilherme e do cemitério, aqui de Foz, só tinha uma torneira de água; todo mundo buscava água pra beber e ainda lavar roupa e fazer tudo. Era tudo muito difícil! E aonde nóis morava, tinha um poço $[\ldots]$ onde as crianças pegava a água, uma água salgada, sem tratamento, sem nada... e a gente vivia ali. Foi difícil, Deus o livre! [sic $]^{55}$

O sr. Ademar, também enfrentou problemas na sua chegada:

[...] sofri aqui, dormi em cima de caminhão toldo. Cheguei aqui eu não tinha conhecimento. Tinha um cara que eu conhecia ele aqui, mas até que eu fui encontrar com ele eu posei várias noites em cima de caminhão toldo aí, não tinha dinheiro pra pagar hotel, né? ${ }^{56}$

Por ser motorista autônomo, mesmo depois de contratado pela UNICON, o Sr. Ademar não tinha direito de se alojar nos conjuntos habitacionais. Ademar narra os problemas que enfrentou:

Fomo morá ali na vila, na Trans-Paraguaia. Ali, uma vila que tem ali na cidade pra cá do batalhão, ali um pouquinho descendo pra baixo, ali um favelão desgramado lá. Morei numa casa quatro pés, só que eu morei só em duas parede e meia e não era forrada a casa. E a água pra tomar eu tinha que levá da usina porque a água lá onde que eu morava não prestava pra tomá. Era um poço lá que a molecada tomava banho dentro dele. Um poço de dois metros de fundura [sic $].{ }^{57}$

Essas são algumas memórias sobre a formação de bairros ao redor do centro da cidade, e sobre as condições vivenciadas por trabalhadores que buscavam de alguma forma ganhar a vida na fronteira. Além dos problemas relativos à moradia, as memórias das pessoas que viveram o processo de instalação do canteiro de obras em Foz do Iguaçu apontam para uma relativização da suposta criação de empregos e dinamização da economia local. É o que apresenta o sr. Carlos:

[...] trabalhei em várias construtoras, na cidade. Aí, com o começo da Itaipu, a influência da Itaipu arruinou muito o serviço, na cidade, porque tinha muitas pessoas que vinha e não conseguia fichar ${ }^{58}$ e trabalhava a qualquer

55 Entrevistado: Carlos. Entrevistadora: Aparecida Darc de Souza, Foz do Iguaçu, 27/03/2007. Ibid., 181-182.

56 Entrevistado: Ademar. Entrevistador: Odirlei Manarin, Foz do Iguaçu, 31/01/2007. Manarin, Peões da barragem, 30-31.

57 Entrevistado: Ademar. Entrevistador: Odirlei Manarin, Foz do Iguaçu, 31/01/2007. Ibid., 32.

58 "Fichar em uma obra" é uma expressão utilizada pelos trabalhadores que significa ser contratado. 
preço. Tinha muita gente. [...]. É que a gente já estava acostumado a ganhar um preço $\mathrm{x}$ e, no caso, tinha que baixar o preço do serviço pra poder competir, porque as pessoas que vinham pra Foz e não conseguiam fichar, eles tinham que voltar pra cidade de origem. Então, eles trabalhavam a qualquer preço, pra poder não voltar. Esse foi o problema que surgiu. ${ }^{59}$

A migração massiva e a consequente desestruturação da vida dos antigos residentes constituíam parte necessária do projeto Itaipu, pois, como bem explicou o Sr. Carlos, o resultado desse processo migratório foi o barateamento dos salários, elemento indispensável para garantir maiores lucros para os empreiteiros, além de aumentar o controle do canteiro de obras mediante a ameaça da perda de emprego para um dos muitos desempregados que ocuparam as fileiras do exército industrial de reserva neste período.

O sr. Adenival realiza, a partir de sua rememoração, uma síntese de três períodos de oferta de emprego na cidade. O primeiro período com muitas vagas de emprego: “[...] de 77 até 80 e alguma coisa, por aí assim, a gente era só ouvir rádio que sabia onde procurar serviço, principalmente na construção civil”; ${ }^{60} \mathrm{O}$ segundo período já é marcado por uma saturação no mercado de trabalho:

[...] Veio a ter alguma dificuldade na década de 80 para cá que começou a ficar meio ruim, não é? Então, muitas pessoas que veio e já ficou por aí mesmo, a cidade começou a inchar, porque a cidade não foi bem projetada, não é? Foi um inchaço, esse foi um dos prejuízos que Itaipu trouxe para a cidade foi essa, um inchaço de gente. ${ }^{61}$

Esse marco histórico estabelecido pelo sr. Adenival, "na década de 80 pra cá...” coincide com o término da etapa de abertura do canal do desvio, que exigiu maior mobilização de força de trabalho. Por fim, o terceiro período é marcado pelo fim da construção, período das demissões finais: "Chegou um certo ponto depois quando foi fechada as etapas dela, que foi dispensado o pessoal, aí começou e a cidade já não tinha mais estrutura para acolher tanta gente”. O

59 Entrevistado: Carlos. Entrevistadora: Aparecida Darc de Souza, Foz do Iguaçu, 27/03/2007. Souza, Formação econômica e social, 183.

$60 \mathrm{O}$ Sr. Adenival, vindo de Minas Gerais, conseguiu seu primeiro nas obras da Itaipu contratado pela Construtora Vila Rica, uma empreiteira subcontratada que ficou responsável por montar a infraestrutura do canteiro de obras. Ele também trabalhou na UNICON em quatro períodos diferentes. Trabalhou ainda na Construtora Taquaruçu, empresa do ex-prefeito da cidade e nesse período ele ajudou a fundar o SITRACOCIFOZ (Sindicato dos Trabalhadores da Construção Civil de Foz do Iguaçu). Entrevistado: Adenival do Carmo Dutra. Entrevistador: Eduardo Gonçalves Ueda, Foz do Iguaçu, 05/05/2019.

61 Entrevistado: Adenival do Carmo Dutra. Entrevistador: Eduardo Gonçalves Ueda, Foz do Iguaçu, 05/05/2019. 
fim das obras de Itaipu e a decadência do setor de construção civil em Foz do Iguaçu (junto com o início do período de estagnação no setor no país) ${ }^{62}$ são decisivos para a mudança da atividade econômica da cidade principalmente para o setor de serviços, com destaque para o turismo, preponderante ainda hoje, cujos postos de trabalho são muitas vezes temporários e o número de vagas insuficientes para empregar a população iguaçuense.

\section{O canteiro de obras: controle e disciplina}

A cláusula 51 do contrato firmado entre a empreiteira UNICON e a Itaipu Binacional determinava o calendário oficial da obra, estabelecendo multas para a empreiteira caso alguma das etapas da construção atrasasse, e bonificações caso a etapa fosse terminada antes do prazo. A UNICON, por sua vez, visando às bonificações, criou seu próprio calendário de obras, que era adiantado em relação ao da Itaipu. As metas de produção foram reorganizadas em um prazo menor do que o estipulado. Essas questões contratuais eram determinantes na "organização de vida e de trabalho colocados para os operários, já que o Consórcio buscava de várias maneiras extrair deles o máximo de sua força de trabalho, para que fosse possível atingir as metas na área de produção". ${ }^{33}$ Assim, o consórcio UNICON estabeleceu uma jornada de trabalho em que a produção era de 24 horas por dia, dividida em dois turnos, entre 10 e 12 horas. ${ }^{64}$

Quando finalmente conseguia um emprego no canteiro de obras, o trabalhador estaria submetido a um rígido esquema de segurança e inteligência. Ao ser contratado, toda a vida pregressa do trabalhador era vasculhada para checar se o mesmo tinha histórico de atuação política. Também se fez presente dentro do canteiro de obras diversas arbitrariedades por parte dos Guardas de Segurança (GS) da Itaipu e UNICON, o que colaborava para uma dinâmica de contratações e demissões, muito eficiente para a obra, mas perturbadora para os trabalhadores.

De acordo com Sessi, a contratação só se efetivava após a passagem pelo recrutamento, onde, entre outros exames, era preenchida a ficha individual. $\mathrm{Na}$ primeira parte da ficha individual eram marcados dados sobre a qualificação civil do candidato, também estavam presentes dados sobre os lugares onde ele havia trabalhado e residido antes da contratação. A Itaipu

62 Campos, Estranhas catedrais, 111-112.

63 Manarin, Peões da barragem, 54.

64 Juvêncio Mazarollo. A Taipa da Injustiça: esbanjamento econômico, drama social e holocausto ecológico em Itaipu (São Paulo, SP: Edições Loyola, 2003), 170. 
podia encaminhar essas informações ao DOPS (Departamento de Ordem Política e Social) para checagem mais profunda da vida do trabalhador. Tal prática tinha como finalidade identificar aqueles trabalhadores que fossem simpáticos à esquerda, ligados a movimentos populares, ou com histórico de militância e organização sindical. Como aponta Rosa Maria Cardoso da Cunha, embora já houvesse alianças entre o empresariado e as forças de segurança antes da ditadura, sob os governos militares essa aliança produziu um fenômeno inédito: "um novo regime fabril, baseado na vigilância e controle militarizados para a obtenção da maior taxa de exploração da força de trabalho, articulado a um novo regime de acumulação". ${ }^{65}$

Quando um Guarda de Segurança detinha um trabalhador por algum motivo e tinha que encaminhá-lo para outro setor, era produzido um documento chamado "recibo de pessoa. ${ }^{6}$ Segundo Sessi, esse documento resguardava esses guardas de qualquer problema que tal prisão poderia gerar ao trabalhador, como lesões, torturas ou, eventualmente, a morte do indivíduo. A emissão de um recibo de pessoa colocava os trabalhadores em uma situação peculiar, pois enquanto o recibo de pessoa estivesse vigente, as normas trabalhistas, que deveriam resguardar o operário, estariam suspensas: "neste caso, tinha-se não um trabalhador, 'mas um suspeito' passivo a seguir para o mundo dos criminosos". ${ }^{67}$

Essa situação se torna ainda mais problemática quando o autor evidencia que a condução de um trabalhador detido à polícia funcionava como válvula de escape para a resolução de conflitos internos:

Por exemplo, no dia 10 de abril de 1981, um trabalhador da Itamon foi conduzido à Delegacia de Polícia, e a descrição do motivo da prisão expressa que ele 'tentou se jogar-se debaixo dos veículos que passavam na Barreira de Controle, às oo:00 hora de hoje: Motivo: Falecimento da mãe (sic)' (CDI 9191F 0066). E quanto às condiç̃es físicas do preso descritas no recibo de pessoa na hora da entrega à Delegacia, o Guarda de Segurança afirmava que estavam 'normais'. ${ }^{68}$

Ao ser encaminhado para a polícia o trabalhador seria invariavelmente demitido, pois um recibo de pessoa emitido pelas Agências de Segurança da

65 Maria Rosa Cardoso da Cunha, "Violações de direitos humanos de trabalhadores”, em Relatório: textos temáticos, vol. 2, Comissão Nacional da Verdade (Brasília: CNV, 2014), 68.

66 Este é um procedimento típico de instituições militares. Para outras práticas das agências de segurança e sua semelhança e relações com o ethos militar consulte:

Sessi, "O povo do abismo", 2015.

67 Ibid., 143.

68 Ibid., 135. 
Itaipu ou UNICON não tinha validade para a polícia, “[... assim, o elo era rompido, e a polícia, como já explicitado, não devolveria um preso a uma empresa cuja lógica sob a ótica policial não era detentora desses protocolos”. ${ }^{69}$ Portanto, por mínimas que fossem as circunstâncias que originam o documento, ou se fosse o caso de apenas uma averiguação, “[ [..] o trabalhador seguia normalmente à polícia para prestar suas declarações de maneira informal, sem o recibo de pessoa, e sem ser intimado via ofício. Este fato inclusive deixava-o em condição de ausente na frente de trabalho". ${ }^{70}$

Em um relatório de 28 de agosto de 1980 produzido pela agência de segurança da UNICON, Carlos, um motorista, “[ [... iniciou uma discussão com seus chefes, alegando que não tinha horário adequado para suas refeições, em face de estar fazendo plantões ininterruptos; segundo a ocorrência, plantões de 24 horas”. ${ }^{71}$ Os Guardas de Segurança, em seu relatório, alegaram que o trabalhador havia faltado com respeito e sido insubordinado com seus chefes. Carlos foi preso pelos guardas e encaminhado para um Posto Policial. De acordo com Sessi, essas pressões no ambiente de trabalho, que em alguns casos significavam o impedimento do trabalhador de se alimentar, eram uma forma:

[...] de obrigá-lo a uma atitude de rompante, à qual qualquer pessoa pode estar sujeita; e mediante isso, providenciar o recolhimento do mesmo para um processo de demissão, e assim a contratação de outro trabalhador, e a concorrência de um processo idêntico ao exposto. ${ }^{72}$

Essas ações por parte dos Guardas de Segurança mostram que as agências de segurança extrapolavam suas funções, exercendo controle opressivo sobre os trabalhadores. O que também colabora para uma dinâmica de contratações e demissões própria, na qual, de um lado havia um enorme exército industrial de reserva, pessoas que passaram a compor periferias urbanas sem infraestrutura mínima, que exerciam pressão sobre os contratados, forçandoos a se adequarem aos padrões exigidos pela Itaipu; e do outro lado, o emprego em Itaipu ou nos consórcios significava a submissão às pressões internas, jornadas de trabalho exaustivas e a sujeição às arbitrariedades dos guardas, que criavam condições de estresse contínuo, o que potencializava o risco de acidentes.

De acordo com Lima, entre o início da construção e o ano de 1979, 40 acidentes fatais teriam sido registrados em Itaipu, número baixo se

\footnotetext{
69 Ibid., 134.

70 Ibid., 134.

71 Ibid., 214.

72 Ibid., 215.
} 
considerada a quantidade de operários na obra. Entretanto, os registros nacionais indicam que o número de acidentes de trabalho, inclusive os fatais, foi extremamente alto ao longo da ditadura civil-militar brasileira. Na década de 1970, com dados da OIT, a Comissão Nacional da Verdade destaca que o Brasil havia se tornado "campeão mundial em acidentes de trabalho". ${ }^{73} \mathrm{Em}$ 1980, de acordo com Campos, o próprio presidente da República ressaltou, durante uma cerimônia, "que o país era recordista em estatísticas de acidentes de trabalho, registrando 1,5 milhões de casos anualmente, e que a indústria da construção tinha um papel central nessa estatística”. ${ }^{74}$ Considerando as dimensões das obras de Itaipu, o risco de acidentes era elevado. Manarin destaca que "não ter nenhuma ocorrência de acidente de trabalho na ficha dos operários registrados no Consórcio UNICON, habilitava-os a disputar, entre os anos de 1981 e 1982, o concurso de ‘Operário Padrão' daquele ano”. ${ }^{75}$

Soma-se a essa dinâmica de contratações e demissões o fato de que em cada etapa da construção era preciso uma quantidade de trabalhadores com determinadas funções. O término de uma fase podia significar que algumas funções deixavam de ser necessárias e, com isso, muitos trabalhadores poderiam ser demitidos ou, no melhor dos casos, realocados. Aqueles que mostravam ter se adequado ao padrão exigido talvez poderiam continuar empregados, geralmente realocados. Aqueles que eram vítimas de acidentes, se recusassem fazer hora-extra, ou não podiam desenvolver as funções requeridas na nova etapa certamente seriam demitidos, e novos trabalhadores seriam contratados para viver nesse ambiente de pressão constante. Nesse pano de fundo, estabelece-se uma relação contraditória entre os operários e os dirigentes e técnicos, já que “os técnicos superiores ganhavam por produção, enquanto que os demais trabalhadores recebiam apenas o salário mensal". ${ }^{76} \mathrm{Ou}$ seja, atender as metas de produção significava para os trabalhadores ficarem expostos às demissões mais rapidamente no fim da etapa, enquanto que para os superiores significava um aumento de renda.

Evidencia-se, portanto, que se o calendário de obras era cumprido muitas vezes com antecedência, isto não se dava por um compromisso pelo desenvolvimento nacional entre operários, Guardas de Segurança, feitores, técnicos, empreiteiros e militares. Pelo contrário, o Canteiro de Obras de Itaipu foi palco do antagonismo de classes que se expressa em disputas pelo

73 Maria Rosa Cardoso da Cunha. "Civis que colaboraram com a ditadura", em Relatório: textos temáticos, vol. 2, Comissão Nacional da Verdade (Brasília: CNV, 2014), 325.

74 Campos, Estranhas catedrais, 359.

75 Manarin, Peões da Barragem, 68.

76 Sessi, "O povo do abismo", 179. 
controle do processo de trabalho, paralisações e greves, mas também pelas imposições da administração para disciplinar a força de trabalho com forte controle e violenta repressão aos trabalhadores.

\section{Considerações finais}

As fontes aqui analisadas indicam um amplo esforço por parte do consórcio de empreiteiras e pela administração da obra para a construção e a preservação de uma memória institucional profundamente articulada com o discurso dos chefes de estado do período e que se caracteriza por relacionar a construção de Itaipu com temas como: desenvolvimento nacional, fortalecimento do setor elétrico como base para o crescimento industrial, eficiência técnica, heroísmo, integração entre as nacionalidades e harmonia nas relações de trabalho. A presença dos militares no poder e na administração da Itaipu projetava a mensagem da garantia da ordem e da disciplina.

A atuação dos sistemas de segurança envolvidos na obra, como destacou Sessi, contribuíram significativamente para efetivar esse controle tanto nas vilas quanto no canteiro de obras ${ }^{77}$ de forma a garantir que os trabalhadores estivessem sujeitos a dobrar turnos, a se submeter ao ritmo intenso de produção em um ambiente de precarização da segurança do trabalho que intensificava os riscos de acidentes. O rígido sistema de controle e repressão implantado, como destaca Silva, expressaram a integração entre o controle empresarial e o controle político na lógica da Segurança Nacional, ${ }^{78}$ e contribuiu profundamente para dificultar e reprimir os caminhos da organização operária. Em 1975, os trabalhadores da Itaipu e da CBPO começaram a organizar uma greve, e o movimento foi intensamente vasculhado e acompanhado pela atuação conjunta das Agências de Segurança brasileira e paraguaia de Itaipu. A greve realizada em 1987 pelos trabalhadores dos consórcios UNICON e ITAMON, evidenciando os esforços da reivindicação por aumento salarial, também mobilizou o sistema repressivo. ${ }^{79}$

Os registros aqui analisados expressam a preocupação por parte da administração na época da construção por controlar as representações em

77 Ibid., 29-30.

78 Jussaramar da Silva, “A Usina de Itaipu e a Operação Condor: o outro lado das relações bilaterais Brasil-Paraguai (1973-1987)” (Dissertação - História, PUC$\mathrm{SP}, 2010), 128$.

79 Ibid., 130. 
torno de Itaipu, atualmente organizada na forma de uma memória institucional que situa os trabalhadores nos marcos técnicos de construção da barragem e atribui a eles interesses e motivações ligadas à produtividade, eficiência e patriotismo na construção da usina hidrelétrica, atrelando-os dessa forma ao discurso de desenvolvimento nacional.

Por outro lado, o aumento da realização de entrevistas com antigos trabalhadores da obra por parte dos pesquisadores tem possibilitado a identificação de evidências destoantes dessa memória institucional homogeneizada. $\mathrm{O}$ confronto entre esses registros e as entrevistas realizadas por diferentes pesquisadores permite situar o processo que buscou invisibilizar a experiência dos trabalhadores que migraram para Foz do Iguaçu em busca de melhores condições de vida. A migração massiva para a cidade criou condições favoráveis às empreiteiras e desfavoráveis aos trabalhadores que, atingidos pelo desemprego e pelo custo de vida elevado, enfrentaram dificuldades diversas até conseguirem a contratação na obra, onde passaram a vivenciar um rígido sistema de controle e repressão por parte das agências de segurança das empreiteiras e da própria Itaipu, submetidos a jornadas exaustivas de trabalho, com grande risco de acidentes, além da insegurança da permanência no emprego.

O estudo aqui apresentado constitui, portanto, mais um esforço no intuito de contribuir para as investigações sobre o mundo do trabalho na construção da Itaipu Binacional ao evidenciar não apenas a existência de memórias divergentes sobre o papel dos trabalhadores na construção, mas demonstrando os mecanismos da elaboração e perpetuação de uma memória dominante e seu esforço de silenciamento sobre outras memórias capazes de revelar muitas das questões relacionadas às condições de vida e de trabalho no contexto da construção da usina.

Finalmente, a maior parte dos estudos identificados pela presente pesquisa foi produzida por brasileiros e possuem o lado brasileiro da Itaipu como foco de investigação: seja em termos de avaliação do impacto ambiental, seja pelos diferentes grupos sociais (camponeses, indígenas, moradores, trabalhadores) atingidos ou envolvidos na construção da usina, seja na discussão geopolítica. Dessa forma, ainda se faz necessário o aprofundamento no tema com um enfoque que permita a análise conjunta da administração binacional e sua articulação com a atuação dos consórcios empresariais dos dois países, assim como as relações enfrentadas e construídas entre os trabalhadores das diferentes nacionalidades. 
Title: A Farda e o Fardo. Memories about the World of Labour in the Construction of Itaipu Binational Hydroelectric Plant (1975-1991)

Abstract: This article aims to demonstrate the existence of disputes over the memory about the place and the role of workers in the construction of Itaipu Binational Hydroelectric Plant in the border between Brazil and Paraguay from the 1970s up to the 1990s. Drawing upon the analysis of speeches and interviews delivered over the years by authorities related to the administration of the work and by heads of state, as well as internal newsletters published by the consortium of contractors UNICON, we intend to highlight the effort by the construction administration, and by members of the military regime, to control - then and now - the narrative about the building and also to define even the workers' memories. Finally, we will discuss how the interviews held with employees have revealed other perspectives that contributed to a more in-depth debate and analysis about the labor world related subjects.

Keywords: memory, workers, Itaipu Binational, civil-military dictatorship

Título: A Farda e o Fardo. Memorias del mundo del trabajo en la construcción de la Central Hidroeléctrica Binacional de Itaipú (19751991)

Resumen: Este artículo pretende demostrar la existencia de disputas alrededor de una memoria sobre el lugar y el papel de los trabajadores en la construcción de la Usina Hidroeléctrica Binacional de Itaipu en la frontera entre Brasil y Paraguay en las décadas de 1970 hasta 1990. A partir de análisis de discursos y entrevistas concedidas al largo de la construcción de la hidroeléctrica por autoridades relacionadas a la administración de la obra y por jefes de Estado, además de las publicaciones del informativo de circulación interna, pretendemos resaltar el esfuerzo realizado por la administración y por miembros del régimen militar, para controlar - en la época y también ahora - la narrativa en torno de la construcción y definir una memoria de los trabajadores. Finalmente, discutiremos como la realización de entrevistas con trabajadores ha revelado otras perspectivas que contribuyen para la profundización de los análisis sobre los temas relacionados con el mundo del trabajo.

Palabras clave: memoria, trabajadores, Itaipu Binacional, dictadura civil-militar 